\title{
Current technology for identifying dental implants: a narrative review
}

\author{
Mohammad Ali Saghiri ${ }^{1} 2^{*}$, Peter Freag ${ }^{3}$, Amir Fakhrzadeh ${ }^{4}$, Ali Mohammad Saghiri ${ }^{5}$ and Jessica Eid ${ }^{3}$
}

\begin{abstract}
Background: This paper outlines the current status and mechanism for identifying dental implants, with emphasis on future direction and updated technology, and covers the existing factors influencing the identification of implant systems.

Main body: A search was performed on the current methods of identifying dental implants between January 2000 through Feb 2020 using online databases for articles published in English. The search was performed using the Google, Rutgers library, PubMed, MEDLINE databases via OVID using the following keywords: implant types identification by x-ray imaging, forensic identification of dental implant, surface types, threaded, non-threaded, software identification, recent technologies, which evaluated different methods in the identification of dental implants and its clinical importance for the dentist and the patient. Of the 387 articles found in initial search results, 10 met the inclusion criteria set for this review. These 10 studies were directly related to the identification of different implant systems. Many studies have indicated identifying dental implants as problematic due to many confounding factors, and the difficulty in finding the specific parts for the dental implant itself. The contribution of digital dentistry is critical. Factors like increasing number of implant manufacturers, dental tourism, and cost, make it difficult to detect and match dental implants by dentists during the chairside time.

Conclusion: These factors give rise to the need for a new system to help clinicians in decision making. Artificial intelligence seems to have shown potential to help in this case. However, detailed regulatory mechanisms are still needed for diagnosis and analysis.
\end{abstract}

Keywords: Automated identification, Dental implants, Forensic, Restorations, Tourism, X-ray

\section{Background}

Dental implants have become a popular choice of treatment in replacing individual lost teeth or entire dentitions. According to the American College of Prosthodontists (A, people with low income or education have fewer remaining teeth (ACP 2020). Also, 27.27\% of seniors over age 65 have no remaining teeth (NIH 2020). Every year, more than 800,000 individual implants are installed in the United States (US), and more than 1.8 million in the European Union (EU) (Insights et al. 2027).

\footnotetext{
*Correspondence: saghiri@gmail.com

1 Department of Restorative Dentistry, Rutgers School of Dental Medicine, MSB C639A, 185 South Orange Avenue, Newark, NJ 07103, USA

Full list of author information is available at the end of the article
}

This number is expected to increase considerably (NIH 2020) due to an increase in the geriatric population and the number of general dentists and specialists performing the procedure. Dental implant therapy is an invasive, lengthy, and precise procedure. Each of the components used in this process are specific to the original implant down to the manufacturer, type and size since most implant companies have a unique library of implant designs, sizes, and platforms. The amount of time it takes for an implant procedure from start to final restoration can be as long as a year in most patients and can cost upwards of $\$ 4000$ per implant (site AAID. 2020). Since an implant contains many different components (Cappare et al. 2019; Takeuchi et al. 2018), it may be difficult to replace it without the knowledge of the implant type. 
The major problem with this process is that clinicians often find patients who have had implants placed in other U.S. dental offices or from areas abroad without any records regarding the identification of the implant system (Fox News 2020). Due to the cost of dental implant therapy in the US, more patients are traveling overseas to have implants placed and subsequently come back to the U.S. to have the implants restored. Currently, identification of the specific implants, without patient records based on radiographic or clinical observation is difficult because of a lack of identifying markers on implants. This problem doesn't just arise during the implant restoration process but is also a cause for concern when implant complications arise. The need for improved methods for accurate implant recognition is widely understood by clinicians and patients who have encountered these issues.

All the currently used methods for implant identification and classification are time-consuming and not very accurate. The most current and frequently used method for identifying dental implants is a website (whatimplantisthat. 2020) that simply provides photos of hundreds of $\mathrm{X}$-rays that clinicians must search through individually to try to help in identifying their patient's implant after they input descriptive features of the implant to narrow down their search field. Lack of an established and efficient system for identifying dental implants, keeping all the different confounding factors including dental tourism, increasing number of implant manufacturers, and cost in mind, has proven to be a hurdle in systemized and timely identification of implants during the chairside time. Developing innovative methods to identify these previously placed implants based on radiographic and clinical data, will spare millions of patients and clinicians the difficult task of deciding whether to proceed with the very invasive unpredictable procedures to remove and replace unidentifiable implants, restore and rehabilitate them with mismatched components. This calls for identification and revaluation of the current technology for identifying dental implants so pave way for it. This paper, therefore, aims to, analyze the existing technology, the new upcoming technology, and its future direction, covering the existing factors influencing the identification of implant systems: manufacturing, patient, and imaging factors.

\section{Main text \\ Materials and methods Purpose}

In this review, the methods for identifying dental implants and their clinical importance for the dentist and the patient are assessed. The factors influencing dental implant survival rates and in extension, leading to an increased need for a centralized database for implants are also assessed. The main aspect of this review is to evaluate the methods in identifying dental implant systems worldwide and describing the limitations within these current methods.

\section{Inclusion and exclusion criteria}

The inclusion criteria were studies accepted and published in the English language between January 2000 through Feb 2020. The inclusion criteria included the scientific in-vivo, in-vitro articles, reviews, systematic reviews, case reports, and clinical trials with controlled study design. Studies were also included that had identified the dental implant systems, implant systems manufacturer identification, forensic radiographic identification, global dental implant market varsity, major implant manufactures, and factors affecting implant maintenance.

The exclusion criteria were studies that were published before January 2000 and through Feb 2020. Criteria also excluded the studies that focused on other restoration types to replace missing teeth. Also, excluded studies that mainly focused on other aspects of implant surgical techniques, impression systems, that do not affect the identification of the implant system.

Search methodology A literature search was performed electronically using the Google, Rutgers library, PubMed, MEDLINE databases via OVID using the keywords mentioned in the PubMed and MeSH headings for articles published in the English language from January 2000 through Oct 2019 that evaluated the method for identification of dental implants and its clinical importance for the dentist and the patient. The keywords included were: implant types, $x$-ray imaging, forensic, implant surface types, threaded, non-threaded, software identification, automated diagnosis. Some of the most relevant article's full texts and reference lists were evaluated for eligibility.

\section{Results}

Of the 387 articles found in initial search results, only 10 met the inclusion criteria set for this review. These 10 studies were directly related to the identification of different implant systems, which are presented in Table 1. The relevant full-text articles and the reference lists of the related articles were evaluated to supplement the search as well. The assessment of the eligibility and finding related data were performed by two reviewers independently.

Upon analysis of the literature selected, different technologies for classifying and building a database for dental implants were found like the Implant Recognition Software (IRS), to identify implants in a person's mouth, a method to identify threaded implants, non-threaded 
Table 1 Implant identification studies included in this study (Michelinakis et al. 2006; Sahiwal et al. 2002a, b, c; Mansour et al. 2019; Nuzzolese et al. 2008; Bush and Miller 2011; Berketa et al. 2010a, b; Mattheos and Janda 2012))

\begin{tabular}{|c|c|c|}
\hline Study & Main aspect & Conclusion \\
\hline Michelinakis et al. (2006) & $\begin{array}{l}\text { "Identification of dental implants through the use of } \\
\text { Implant Recognition Software (IRS)" }\end{array}$ & $\begin{array}{l}\text { The program that was developed provides valuable } \\
\text { information about the identification of implant systems } \\
\text { present in patients' mouths }\end{array}$ \\
\hline Sahiwa et al. (2002a) & $\begin{array}{l}\text { Identification of threaded dental implants from radio- } \\
\text { graphic images }\end{array}$ & $\begin{array}{l}\text { This study shows to be useful in the identification of } \\
\text { threaded dental implants from their radiographic X-ray } \\
\text { images }\end{array}$ \\
\hline Sahiwal et al. (2002b) & $\begin{array}{l}\text { Identification of non-threaded dental implants from radio- } \\
\text { graphic images }\end{array}$ & $\begin{array}{l}\text { Information gained from this study shows to help clinicians } \\
\text { identify non threaded implants from radiographic photos }\end{array}$ \\
\hline Sahiwal et al. (2002c) & Macro design morphology of endosseous dental implants & $\begin{array}{l}\text { Study offers clinicians basic information of the design of } \\
\text { selected dental implants. Such information can aid the } \\
\text { radiographic identification of these implants }\end{array}$ \\
\hline Mansour et al. (2019) & $\begin{array}{l}\text { New aspects of dental implants and DNA technology in } \\
\text { human identification }\end{array}$ & $\begin{array}{l}\text { The dental implant manufacturer database can be very sup- } \\
\text { portive and represent additional reference data for dental } \\
\text { implant classification }\end{array}$ \\
\hline Nuzzolese et al. (2008) & $\begin{array}{l}\text { Radiographic dental implants recognition for geographic } \\
\text { evaluation in human identification }\end{array}$ & $\begin{array}{l}\text { The study links implant type to specific geographic location } \\
\text { within Italy. The radiographic images provided should } \\
\text { show benefits in the forensic filed and the prosthodontic } \\
\text { filed to identify pre-existing implants which they may } \\
\text { discover from their radiographic images }\end{array}$ \\
\hline Berketa et al. (2010a) & $\begin{array}{l}\text { The use of batch numbers which survive within dental } \\
\text { implants following incineration as an aid to identification }\end{array}$ & $\begin{array}{l}\text { If the companies constructing implants were to place } \\
\text { individual serial numbers rather than batch numbers will } \\
\text { be more efficient }\end{array}$ \\
\hline Berketa et al. (2010b) & $\begin{array}{l}\text { Radiographic recognition of dental implants as an aid to } \\
\text { identifying the deceased }\end{array}$ & $\begin{array}{l}\text { The Implant recognition software in its current form was } \\
\text { of little benefit for radiographic assessment of dental } \\
\text { implants for forensic odontologists }\end{array}$ \\
\hline Daher et al. (2009) & Implant treatment record form & $\begin{array}{l}\text { An implant record form is very important. The record form } \\
\text { should be filled out and retained in the patient's files for } \\
\text { future use and implant recall visits }\end{array}$ \\
\hline Mattheos and Janda (2012) & $\begin{array}{l}\text { Case report: managing complications with unidentified } \\
\text { implant system }\end{array}$ & $\begin{array}{l}\text { This case report management of the complication dealing } \\
\text { with unidentified dental implant restoration, and the use } \\
\text { of technology dealing with the problem }\end{array}$ \\
\hline
\end{tabular}

implants using radiographic images, a method to identify the design of selected dental implants, dental implant manufacturer database, a method to identify implants from Italy. The complications arising due to dealing with unidentified implants reiterating the need for a new system was found along with finding a potential solution in terms of a suggestion for companies to place individual serial numbers rather than batch numbers on the implants, and the filling out an implant record file by the patients to keep better tabs of the implants to build a database.

\section{Discussion}

\section{Identification technology for different implant systems}

The articles and studies discussed in this scientific review are distributed as shown in Fig. 1a. G. Michelinakis et al. (2006) created a webpage at Manchester University, United Kingdom, and collected all data available for rootformed implants obtained from the Google search engine 'www.google.co.uk' and the AltaVista search engine 'www.altavista.com', as shown in Table 2. The webpage involved a detailed search of the World Wide Web (web) for implant manufacturing companies, with the initial search period being from November 2002 to June 2003 and updates commenced in February 2004 and ended in April 2004; a total of a 10-month search period. Implant types after April 2004 were not included. The data from this period was classified according to the implant type, body shape, implant design, abutment connection type, threaded or non-threaded, the surface type, polished collar, the diameter and length available for each system. The details of each implant system, according to each manufacturer, were then collected and stored in the IRS. This data, though collected from 21 different countries, produced a total of only 231 different implant designs. IRS ideally made it possible for the dentist and the lab workers to identify each dental implant system. However, because the IRS online tool was only updated during a limited time period, this system is no longer as beneficial as it was during that time.

Another study by Sahiwal et al. (2002a) documented various $\mathrm{x}$-ray photos with different horizontal rotations 


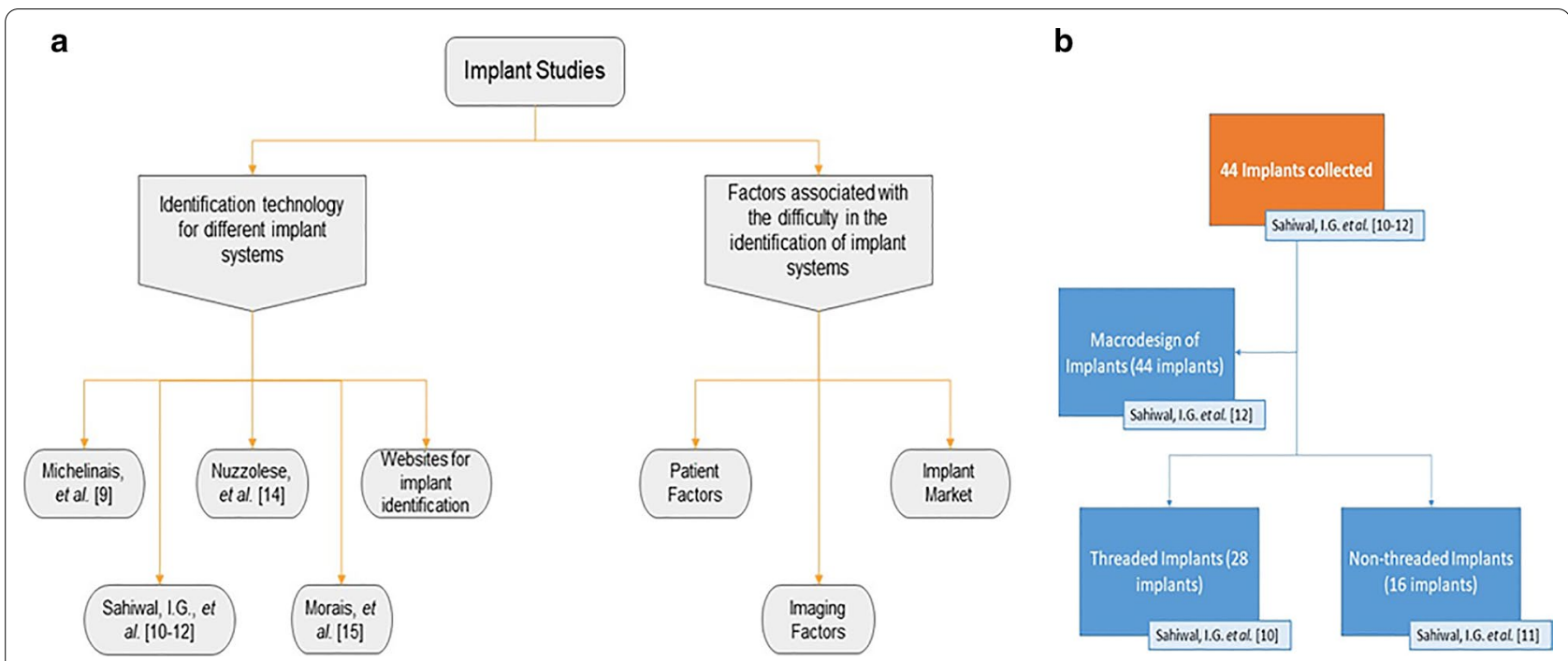

Fig. 1 a Schematic of the studies involved in the review; b Three studies conducted by Sahiwal et al. (Sahiwal et al. 2002a; Sahiwal et al. 2002b; Sahiwal et al. 2002c) describing different types of implants: Threaded and Non-threaded including the macro design of each

and vertical angulations to the $\mathrm{x}$-ray beam for each implant system, shown in Fig. 1b. This study was for the threaded implants identification only. In this study, about forty-four implants " $3.7 \mathrm{~mm} \mathrm{D}$ "10 mm L" were collected, twenty-eight of which identified as threaded from more than fifty implant industry companies. Radiographic $\mathrm{x}$-rays were taken in $0^{\circ}, 30^{\circ}, 60^{\circ}$, and $90^{\circ}$ horizontal rotation with $-20^{\circ},-10^{\circ}, 0^{\circ},+10^{\circ}$, and $+20^{\circ}$ vertical inclination relative to the $\mathrm{x}$-ray beam. This resulted in the production of twenty photos for each implant but at $20^{\circ}$ vertical inclination. However, the $\mathrm{x}$-ray photos were distorted and unrecognizable, so the observation was made only from $-10^{\circ}$ and $+10^{\circ}$ vertical inclination. They made tables describing each coronal part, middle part, apical part of each implant at vertical inclinations of -20 to +20 , and -10 to +10 of the screw chambers. These tables were meant for the dental professional to match the description of their patient's implant $x$-ray to the tables provided in this study to identify what threaded implant they are working with. As for the non-threaded implants, Sahiwal et al. (2002b) documented the features of different types of non-threaded dental implants in which they used the same protocol as described in the threaded study. More than fifty implant manufacturers were contacted, and out of forty-four implant that were donated, sixteen were non-threaded with " $3.7 \mathrm{~mm}$ D*10 mm L" dimensions, as shown in Fig. $1 \mathrm{~b}$.

Sahiwal et al. (2002c) also studied the Macro design and the morphology of endosseous dental implants. In this study forty-four implants of size: "3.75mmD"10 mm" were donated and then classified into threaded and nonthreaded, and tapered and non-tapered implants, as shown in Fig. 1b. They examined each implant individually into 3 sections: coronal third, middle third, and apical third of the fixture. Then a table was formed describing each section of the fixture. This comparative method gives the dentist a database feature for each design and help in the radiographic identification for each system. However, as shown in Table 2, the limitation of all three studies by Sahiwal et al. (2002a, b, c) was that identifying the implants was cumbersome. These tables were limited to the forty-four implants that were donated and there is no software available making it prone to human error. This is not an up to date method and hence a more exact method is still required for more accurate identification of implants.

According to a study by Mansour et al. (2019), possibility of identifying the batch numbers, even if they were not engraved in dental implants, making antemortem dental records of dental implants more easily accessible to establish a comparative dental identification. In addition, the reported case presents the supplementary data yielded through estimating the epigenetic age using DNA (deoxyribonucleic acid) methylation as well as the biogeographical origin using Y-Haplotype and mitochondrial DNA analyses. Our results demonstrate that expanded oral implant investigations that also include implants extraction and comprehensive microscopic measurements can lead to identifying their batch numbers despite the numerous number of implants systems manufactured and distributed worldwide. Data saved by dental implant manufacturers can be very supportive and represent additional reference data for dental identification, when antemortem dental records are still missing. 


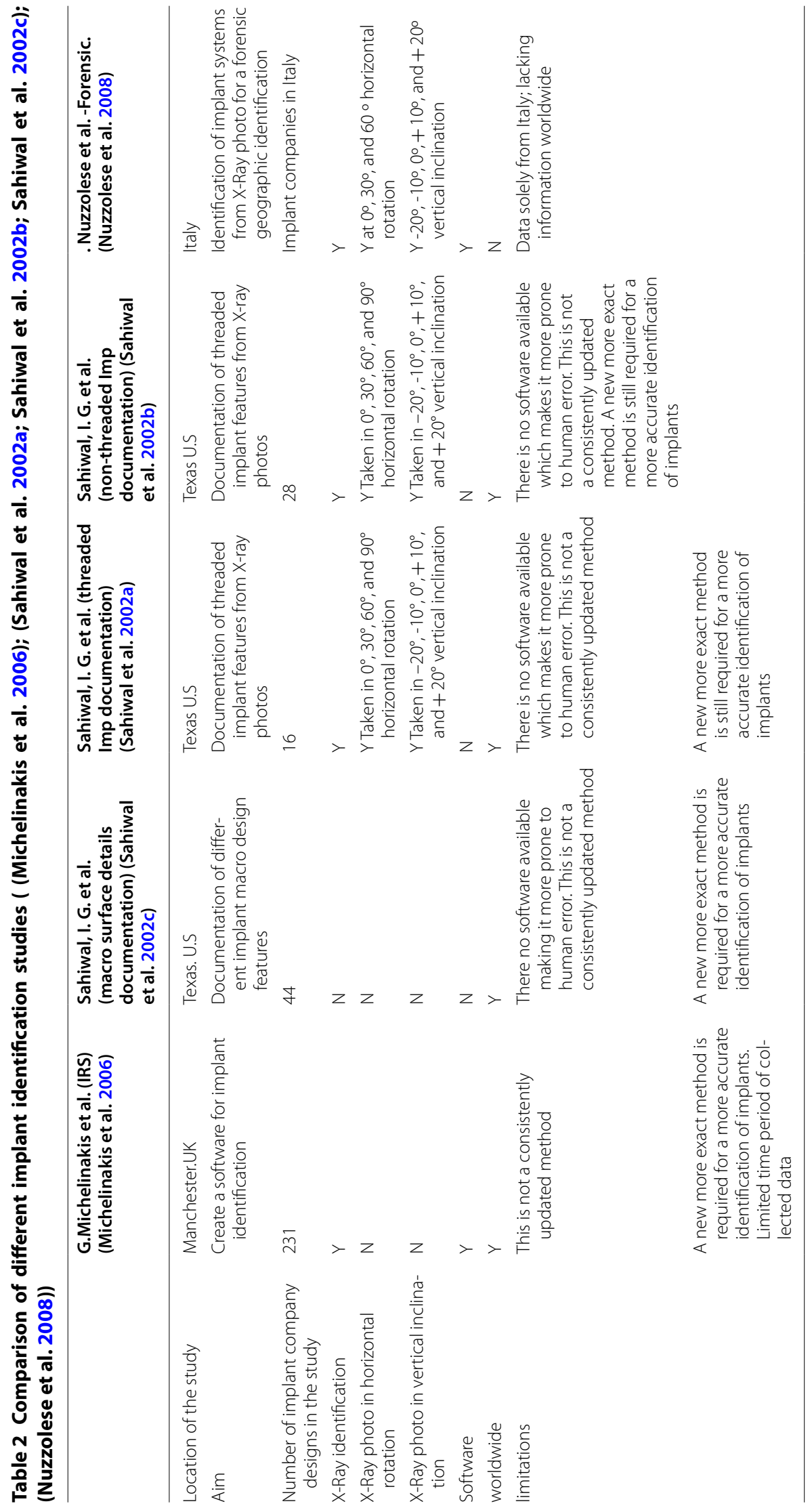


Nuzzolese et al. (2008) studied the radiographic dental implants recognition for geographic evaluation within human identification. This study was carried out in Italy; the researchers created an archive of radiographic photos of Italian dental implants taken at horizontal rotations of $0^{\circ}, 30^{\circ}$, and $60^{\circ}$ and combined with $-20^{\circ},-10^{\circ}, 0^{\circ},+10^{\circ}$, and $+20^{\circ}$ vertical inclination. They summarized the data into fifteen photos for each implant system. The observation was only in a $-10^{\circ}$ and $+10^{\circ}$ vertical inclination; this study shows the survey of the distribution of the implant market over Italy thus give a clue of the geographic identification. However, the implant information was solely collected from Italy, geographically limiting this study.

According to Morais et al. (2015), a dental implant recognition novel computer-aided framework was suggested. They used this method for a segmentation strategy for semi-automatic implant delineation and a machine learning approach for the recognition of an implant model design. Although the segmentation technique was the focus of the recent study, preliminary details of the machine learning approach were also reported. Two different scenarios were used to validate the framework: (ACP 2020) comparison of the semi-automatic contours against implant's manual contours of $125 \mathrm{x}$-ray images; and (NIH 2020) classification of 11 known implants using a large reference database of 601 implants. In experiment $2,91 \%$ of the implants were successfully recognized while reducing the reference database to $5 \%$ of its original size. The segmentation technique achieved accurate implant contours. Although the results of the preliminary classification proved the concept of the current work it had limitations like the lack of detecting distinct features on implants; this software, though a step in the right direction, still needs an expansion of implants details in the database.

The current methods are limited to the dentists worldwide but not only does the dental field benefit from the identification of different implant system but also the forensic field gains significantly by classifying implant systems as it may provide the missing link to complete the picture (Bush and Miller 2011). For example, the identification of a disaster victims from their dental records is a well-established technique. In cases in which dangerous high temperatures from fires causes destruction of the structural integrity of the dentition, implants prove to be the only recognizable features. A study by Berketa et al. (2010a) talks about how efficiency of implant recognition can be increased if the implant manufacturers were to place individual serial numbers rather than batch numbers on them. In another one of his studies (Berketa et al. 2010b), he talks about how the Implant recognition software in its current form was of little benefit for radiographic assessment of dental implants for forensic odontologists. One way to improve this has been suggested by Daher et al. (2009) where they how an Implant Record Form filled by the patients would prove to be highly beneficial in keeping track of them.

Certain websites can be helpful in the task of identifying implants, as mentioned before. Sites such as whatimplantisthat (whatimplantisthat. 2020), Osseosource (OSSEOsource 2020), and Whichimplant (no longer available) are open source search engines that allow identification of implants through its radiographic photos. "Exotic encounters with dental implants: managing complications with unidentified systems" a case report by Mattheos et al. (2012), reported a 55-year-old male patient, with a dental implant from outside the country needed implant therapy. He identified his implant through these websites using his $\mathrm{x}$-rays. A dental implant identification app was also launched three years after the conception of whatimplantisthat.com based on it (Kent Howell 2013). This app made its dental database easily accessible on the go to help better dental care provided by clinicians. In recent times, with the increasing utilization of artificial intelligence (AI) in various fields, a website which uses cloud-based AI to help dentist interpret $\mathrm{x}$-ray images to find 30\% more pathologies by specially developed machine learning algorithms (Tuzoff and Denti 2017). Though currently, the app and site whatimplantisthat.com is the most accurate and time-saving method, the AI website is a step in the right direction, and incorporating its featured to create an implant database will revolutionize this field.

\section{Factors associated with the difficulty in the identification of implant systems Implant market size and manufacture variety (Fig. 2a)}

According to Dental Implants Statistics, the global dental implants market is likely to arrive at USD 13.01 billion by 2023 from USD 9.50 billion in 2018, at a CAGR of 6.5\% (MarketsandMarkets ${ }^{\mathrm{TM}}$ 2023). The need for dental implants is growing; over $69 \%$ of Americans ages 34 to 44 years old have at least one tooth missing. More than 35 million people have an edentulous jaw or both (Gaille 2018). Additionally, according to the National Institute of Dental and Craniofacial Research, 24\% of elderly people above 74 years old already have lost all their teeth (NIH 2020). During the period of 2014 to 2017, major players adopted product launches to strengthen their product portfolio and widen their customer base, followed by agreements, partnerships, and collaborations (Markets et al. 2023). Institute Straumann AG (Straumann) (Switzerland), DENTSPLY Sirona Inc. (DENTSPLY Sirona) (US), Zimmer Biomet Holdings, Inc. (Zimmer Biomet) (US), Danaher Corporation (US), AVINENT Implant System (AVINENT) (Spain), being the predominant 


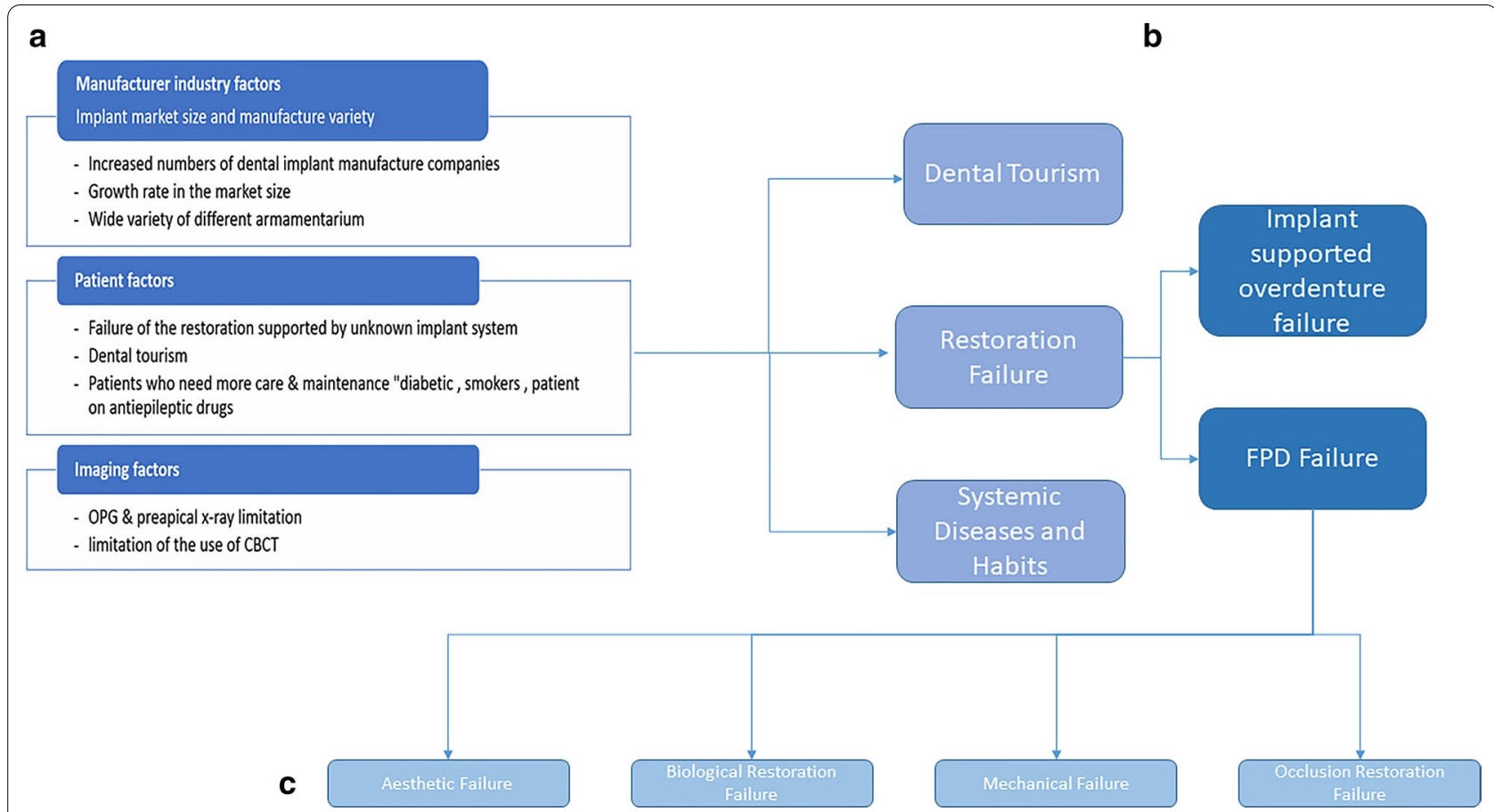

Fig. 2 a Summarization of the factors associated with the complexity of implant identification.b Distribution of patient factors.c The failure types of implant-supported restorations

players in the current dental implant market (Marketwatch 2024). The implants by various companies differ from each other subtly and accurate model is hard to detect even by an experienced eye. The difficulties with the identification of dental implants are increasing along with the rapid exponential growth of its market with the armamentarium for each system varying along with it.

\section{Dental tourism: cost and age (Fig. 2b)}

Dental tourism is a major impacting factor that many clinicians are facing in identifying dental implant systems of each patient. There are many reasons why patients choose to receive implant restorations outside of the United States, first being the cost factor. 3-4 percent of the world's population travels across borders receive healthcare; it is estimated that this industry is growing by 25 percent per year (Aircare Air Ambulance and Medical Escort Services 2020). It is estimated that 1.3 million Americans left the US for medical care in 2016; about 50 percent went to Mexico for dental procedures and another 15 percent traveled for cosmetic procedures (28). The ages of patients vary as well. Most statistics show that older patients are more likely to consider traveling for healthcare, but VISA surveyed over 30,000 people, 18 to 34 years of age, results pointed to about $88 \%$ of the total respondents made trips at least once per year, sometimes three times, for healthcare procedures (28). Statistics show that 400,000 Americans crossed international borders for dental care. According to a study, (Moeller et al. 2010), in 2016, uninsured low-income patients are less likely to receive dental services or may only have nonmajor dental care. The cost factor prevents most of uninsured patients to have dental treatment.

\section{Restoration factors}

Failure of the restoration supported by an unknown implant system (Fig. 2b) Prosthetic failure may be due to an implant supported overdenture failure, FPD (fixed partial denture) failure, biological restoration failure, or an occlusion restoration failure. Failure of the restoration supported by an unknown implant system includes Peri-implantitis, restoration loosening, and fracture and implant structural damage. They may occur in implantsupported single or splinted crowns, bridges, overdentures, or fixed dentures (Gong 2018).

Implant supported overdenture failure (Fig. 2b) According to José Balaguer et al. (2015), overdentures were examined over 95 months (ranging from 36 to 159 months) with an overall success rate of $96.1 \%: 91.9 \%$ in the maxilla and $98.6 \%$ in the mandible, this being a significant difference $(\mathrm{P}<0.05)$. Over the 13-year follow-up, 14 implants failed (3.9\%), 12 due to peri-implantitis, and 2 due to implant fracture average duration of loading before fail- 
ure was 52 months. The survival rate is not perfect, which implies that a dental professional may need to replace the overdenture leading to clinicians needing information pertaining to the implant system which is critical for accurately replacing the denture. According to Vahidi $\mathrm{F}$ et al. (2015), even with the success rate, implant-supported removable prostheses require episodic maintenance making it a critical factor and hence making the need for a systematic classification and database for implants indispensable irrespective of the need for replacement.

Fixed partial denture (FPD) failure According to Bjarni E. Pjetursson et al. (2012), the meta-analysis of these studies indicated an estimated survival of implants supporting FPDs of $95.6 \%$ after 5 years and $93.1 \%$ after 10 years. The survival rate of implant supported FDPs was $95.4 \%$ after 5 years and $80.1 \%$ after 10 years of function. The success rate of metal-ceramic implant-supported FDPs was 96.4\% after 5 years and $93.9 \%$ after 10 years (Sadid-Zadeh et al. 2015). Only $66.4 \%$ of the patients were free of any complications after 5 years. The most frequent complications in all implant supported restorations over the 5-year observation period is shown in Table 3. These mechanical complications can be developed from even a single tooth restoration or fixed partial denture restoration supported by implants. Failure types of implant supported restoration are broadly shown in Fig. 2c.

\section{Aesthetic, biological restoration, mechanical and occlusion restoration failures (Fig. 2c)}

These two factors are correlated. Aesthetic failure due to gingival recession, which is a biological component, over an implant will affect the aesthetic aspect, especially in the front teeth. Aesthetic failures can be categorized as gingival failures or emergence profile failure and white-tissue failures (Fuentealba and Jofre 2015). According to Sailer et al. (2015), the feldspathic based porcelain should be limited to applications in the anterior region due to metal showing and zirconia ceramic

\begin{tabular}{|c|c|}
\hline $\begin{array}{l}\text { Most frequent complications of implant } \\
\text { supported restoration }\end{array}$ & $\begin{array}{l}\text { Percentage } \\
\text { of complications } \\
\text { over } 5 \text { years }\end{array}$ \\
\hline Fractures of veneering material & 13.5 \\
\hline Peri-implantitis/soft tissue complications & 8.5 \\
\hline Loss of access hole restoration & 5.4 \\
\hline Abutment/screw loosening & 5.3 \\
\hline Loss of retention of cemented FPD's & 4.7 \\
\hline
\end{tabular}

crowns should not be considered as a primary option due to their high frequency of technical problems. Avoiding biological failures is critical in maintaining the health of the periodontium. The number of dental implants is increasing, a healthy peri-implant soft and hard tissues are required for the stability and survival of dental implants (Algraffee et al. 2012). Biological restoration failure includes the complication of periimplantitis. The restoration itself can be lacking in the biological component (i.e. implant surface is rough). Daubert et al. (2015) found in his study that one in four patients and one in six implants have peri-implantitis after 11 years. According to Lee CT et al. (2017), periimplant diseases were prevalent and the occurrence of peri-implantitis increased with time. According to Bergmann et al. (2014), dental implants are situated into an ever-changing environment in which teeth can continue to move around but the implants are ankylosed. Teeth may continue to erupt, leaving the implants in infraocclusion or move medially away from an implant which requires modification of the restoration. All these failures are components in which identifying the implant system is essential for everyone.

\section{Systemic conditions and habits (Fig. 2b)}

The systemic conditions and the drugs used in the treatment of various conditions influence the implant restoration success rate; also, habits like smoking and bruxism have an impact on the success of the restoration. According to Manor et al. (2017), medically compromised people go ahead with surgery increasing failure rate. Certain medications involved in medical treatment can also be a factor. According to Chrcanovic et al. (2016), antidepressants are a statistically significant predictor for implant failure. Smoking is another factor as it is shown that implant restorations in smokers have a high failure rate, risk of postoperative infection, and marginal bone loss. With that said, smoking is not an absolute contraindication for implant treatment, but patients should be advised of the high risk of failure (Keenan and Veitz-Keenan 2016). Diabetes mellitus is also associated with a high risk of peri-implantitis, independently of smoking, but not with peri-implant mucositis, according to Monje et al. (2017). More research must be done because there is not yet a clear association between diabetes and implant failure (Naujokat et al. 2016). Bruxism may also significantly increase the implant failure rate and the complications of implant-supported restorations (Chatzopoulos and Wolff 2018). These conditions and habits hence affect the implant success rate and make their identification important. 


\section{Imaging factors (Fig. 2a)}

The problem in identifying an implant with a standard $2 \mathrm{D}$ (NIH 2020) $\mathrm{x}$-ray is that 3D (Insights et al. 2027) spatial information is necessary for identification (Perlea et al. 2016). Additionally, the unknown implant insertion angle inside the jawbone, the horizontal rotation, the vertical inclination, and the direction of the $x$-ray beam were also contributing factors that need to be accounted for while photographing and documenting the data as it is important for the interpretation and identification of the implant $x$-ray photo as shown by Indira G. Sahiwal et al. (2002a, b). Choi JW et al. (2011) confirmed that for a 3D $x$-ray, the use of CBCT (cone beam computed tomography-diagnostic aid used when the conventional $\mathrm{x}$-rays fail as a diagnostic tool (Shah et al. 2014)) should be preferred over a CT (computed tomography) image but it has a high radiation dose. According to Michele $\mathrm{M}$ Vidor et al. (2017), radiographic image of the boneimplant interface is influenced by two factors, the radiographic system, and the processing filter employed. The results from this study are that conventional radiographs or digital images with application of high-pass filters such as "Caries2" and "Endo" could help enhance diagnosis on the implant-bone interface on intraoral radiographs so it could help too in the identification of different implant systems and hence aid in the identification of different implant systems. Its flexibility with output formats, calibration of magnified images, and instantaneous results make it a highly efficient method (Gupta et al. 2015). According to Narra et al. (2015), Micro-CT was found to be a valuable tool for the morphologic evaluation of retrieved dental implants. Therefore, imaging factors influence the identification and indexing of current dental implants.

\section{Conclusion}

- According to the growing rate of the implant market and the significant increase of the implant manufacturer's design, the identification of different implant systems has become a critical issue. Not only the growth of different implant designs has been deemed an issue but also the global increase in patients in need of treatment.

- The maintenance factor needed in the post-implant treatment for every system is different within each armamentarium therefore; the clinicians and the lab technicians need to know exactly which system they are dealing with. Implants are a restoration that needs maintenance. Some patients who have medical conditions like diabetes and epilepsy are at greater risk for implant restoration failure. These patients need maintenance of periodontal health, which makes the identification for the implant restoration critical.

- The development of a new and extensive database for implants is vital for successful implant therapies. The current technologies include limited databanks either due to lack of samples or geographical restrictions. Others are either with a limited period or only give 2D data where 3D information for implants are needed. Given the lacking current technology, keeping a tab on all the implants is very difficult and development needs to be made to design a more efficient, exhaustive, and accurate system.

- The identification based on radiographic imaging needs more information about the horizontal rotation and vertical inclination of the fixture inside the jawbone. Digital radiography has shown to be highly effective in taking implant images due to its calibration of magnified images. Using digital imaging radiographic photos with high resolution and high pixelation is important to make the identification easier. Software programs or mobile applications based on documentation technology make it easier and more efficient for the dentist to use which saves significant chair side time and cost. More research is needed to cover the market variety and the update for the database is mandatory and essential for the awareness of dental implant global production.
Abbreviations

ADA: American dental association; ACP: American college of prosthodontists; US: United States of America; EU: European union; IRS: Implant recognition software; UK: United Kingdom A; DNA: Deoxyribonucleic acid; FDP: Fixed partial denture; 2D: 2 Dimensional; 3D: 3 Dimensional; CBCT: Cone beam computed tomography; CT: Computed tomography.

\section{Acknowledgements}

This publication is dedicated to the memory of Dr. H. Afsar Lajevardi (Saghiri and Saghiri 2017), a legendary Pediatrician (1953-2015). We will never forget Dr. H Afsar Lajevardi's kindness and support. The views expressed in this paper are those of the authors and do not necessarily reflect the views or policies of the affiliated organizations. The authors hereby announced that they have active cooperation in this scientific study and preparation of the present manuscript. The Authors confirm that they have no financial i nvolvement with any commercial company or organization with direct financial interest regarding the materials used in this study. The Authors confirm that they have nothing to disclose. MAS acknowledges being a recipient of the New jersey health foundation award.

\section{Authors' contributions}

Designed: MAS, PF. Conducted: MAS, PF, AF, Analyzed/interpreted data: MAS, PF, AF Wrote the article: MAS, JE. Proofed/revised article: MAS, PF, AF, JE. All authors have read and approved the manuscript.

\section{Funding}

Not applicable. 


\section{Availability of data and material}

The datasets used and/or analyzed during the current study are available from the corresponding author on reasonable request.

\section{Ethics approval and consent to participate}

Not applicable.

\section{Consent for publication}

Not applicable.

\section{Competing interests}

The authors declare that they have no competing interests.

\section{Author details}

${ }^{1}$ Department of Restorative Dentistry, Rutgers School of Dental Medicine, MSB C639A, 185 South Orange Avenue, Newark, NJ 07103, USA. ${ }^{2}$ Department of Endodontics, University of the Pacific, Arthur A. Dugoni School of Dentistry, San Francisco, CA, USA. ${ }^{3}$ Newark, NJ, USA. ${ }^{4}$ Department of Periodontics, Rutgers School of Dental Medicine, Newark, NJ, USA. ${ }^{5}$ Sector of Angiogenesis Regenerative Medicine, Dr. Hajar Afsar Lajevardi Dental Material and Devices Group (ADMD), Hackensack, NJ, USA.

Received: 21 October 2020 Accepted: 14 December 2020

Published online: 06 January 2021

\section{References}

ACP. American collage of prosthodontics. Facts \& Figures. https://www.gotoa pro.org/facts-figures/. Accessed 28 Aug 2020

Aircare Air Ambulance and Medical Escort Services. Top Dental Tourism Statistics for Dental Procedures Abroad 7/27/2017 [updated September 26, 2017. http://www.airambulanceone.com/medical-tourism-trends-facts -figures/. Accessed 28 Aug 2020

Algraffee H, Borumandi F, Cascarini L (2012) Peri-implantitis. Br J Oral Maxillofac Surg. 50(8):689

Balaguer J, Ata-Ali J, Penarrocha-Oltra D, Garcia B, Penarrocha-Diago M (2015) Long-term survival rates of implants supporting overdentures. J Oral Implantol 41(2):173-177

Bergmann RH (2014) Occlusal considerations for dental implant restorations. Compend Contin Educ Dent. 35(7):455-8

Berketa JW, Hirsch RS, Higgins D, James H (2010b) Radiographic recognition of dental implants as an aid to identifying the deceased. J Forensic Sci 55(1):66-70

Berketa J, James H, Marino V (2010a) Survival of batch numbers within dental implants following incineration as an aid to identification. J Forensic Odontostomatol 28(1):1-4

Brandon Gaille. 17 Dental Implant Industry Statistics and Trends Aug 5, 2018. https://brandongaille.com/17-dental-implant-industry-statistics-andtrends/. Accessed 28 Aug 2020

Bush M, Miller R (2011) The crash of colgan air flight 3407: advanced techniques in victim identification. J Am Dent Assoc 142(12):1352-1356

Cappare P, Sannino G, Minoli M, Montemezzi P, Ferrini F (2019) Conventional versus digital impressions for full arch screw-retained maxillary rehabilitations: a randomized clinical trial. Int J Environ Res Public Health 16(5):829

Chatzopoulos GS, Wolff LF. Symptoms of temporomandibular disorder, selfreported bruxism, and the risk of implant failure: a retrospective analysis. Cranio. 2018:1-8.

Choi JW (2011) Assessment of panoramic radiography as a national oral examination tool: review of the literature. Imaging Sci Dent 41(1):1-6

Chrcanovic BR, Kisch J, Albrektsson T, Wennerberg A (2016) Factors influencing early dental implant failures. J Dent Res 95(9):995-1002

Daher T, Goodacre CJ, Morgano SM (2009) Implant treatment record form. J Prosthodont Implant, Esthetic Reconst Dent 18(4):366-368

Daubert DM, Weinstein BF, Bordin S, Leroux BG, Flemming TF (2015) Prevalence and predictive factors for peri-implant disease and implant failure: a cross-sectional analysis. J Periodontol 86(3):337-347

Dr. Kent Howell DMD MaDNFD, MS. Dental implant identification mobile app Nov 22nd, 2013. https://www.dentistryiq.com/dentistry/article/16353 808/dental-implant-identification-mobile-app. Accessed 28 Aug 2020
Fox News. Dental tourism could save you big money 2013. https://www.foxne ws.com/travel/dental-tourism-could-save-you-big-money Accessed 28 Aug 2020

Fuentealba R, Jofre J (2015) Esthetic failure in implant dentistry. Dent Clin North Am 59(1):227-234

Gong P (2018) Role of occlusion in complications of implant rehabilitation. Zhonghua Kou Qiang Yi Xue Za Zhi 53(12):800-804

Gupta S, Patil N, Solanki J, Singh R, Laller S (2015) Oral implant imaging: a review. Malay J Med Sci MJMS 22(3):7-17

Keenan JR, Veitz-Keenan A (2016) The impact of smoking on failure rates, postoperative infection and marginal bone loss of dental implants. Evid Based Dent 17(1):4-5

Lee CT, Huang YW, Zhu L, Weltman R (2017) Prevalences of peri-implantitis and peri-implant mucositis: systematic review and meta-analysis. J Dent $62: 1-12$

Manor Y, Simon R, Haim D, Garfunkel A, Moses O (2017) Dental implants in medically complex patients-a retrospective study. Clin Oral Investig 21(2):701-708

Mansour H, Sperhake JP, Bekaert B, Krebs O, Friedrich P, Fuhrmann A et al (2019) New aspects of dental implants and DNA technology in human identification. Forensic Sci Int 302:109926

MarketAnd Markets. Dental Implants and Prosthesis Market by Type (Dental Implants, Bridge, Crown, Abutment, Dentures, Veneers, Inlay \& Onlays), Material (Titanium, Zirconium, Metal, Ceramic, Porcelain Fused To Metal), Type of Facility - Global Forecast to 20232019 https://www.marketsand markets.com/Market-Reports/dental-implants-prosthetics-market-695. html. Accessed 28 Aug 2020

MarketsandMarkets ${ }^{\mathrm{TM}}$. Dental Implants and Prosthesis Market by Type (Dental Implants, Bridge, Crown, Abutment, Dentures, Veneers, Inlay \& Onlays), Material (Titanium, Zirconium, Metal, Ceramic, Porcelain Fused To Metal), Type of Facility - Global Forecast to 2023.

Marketwatch. Dental Implants Market : Global Trends, Share, Growth, Opportunity And 2024 2019. https://www.marketwatch.com/press-release/denta l-implants-market-global-trends-share-growth-opportunity-and-20242019-11-15. Accessed 28 Aug 2020

Mattheos N, Janda MS (2012) Exotic encounters with dental implants: managing complications with unidentified systems. Aust Dent J 57(2):236-242

Michelinakis G, Sharrock A, Barclay C (2006) Identification of dental implants through the use of implant recognition software (IRS). Int Dent J 56:203-208

Moeller JF, Chen H, Manski RJ (2010) Investing in preventive dental care for the medicare population: a preliminary analysis. Am J Public Health 100(11):2262-2269

Monje A, Catena A, Borgnakke WS (2017) Association between diabetes mellitus/hyperglycaemia and peri-implant diseases: Systematic review and meta-analysis. J Clin Periodontol 44(6):636-648

Morais P, Queirós S, Moreira AHJ, Ferreira A, Ferreira E, Duque D, et al. Computer-aided recognition of dental implants in X-ray images: SPIE; 2015.

NIH.National Institute of Craniofacial Research. https://www.nidcr.nih.gov/ research/data-statistics/tooth-loss/seniors. Accessed 28 Aug 2020

Narra N, Antalainen AK, Zipprich H, Sandor GK, Wolff J (2015) Microcomputed tomography-based assessment of retrieved dental implants. Int J Oral Maxillofac Implants 30(2):308-314

Naujokat H, Kunzendorf B, Wiltfang J (2016) Dental implants and diabetes mellitus-a systematic review. Int J Implant Dent 2(1):5

Nuzzolese E, Lusito S, Solarino B, Di Vella G (2008) Radiographic dental implants recognition for geographic evaluation in human identification. $J$ Forensic Odontostomatol 26(1):8-11

OSSEOsource. http://www.osseosource.com/dental-implants/ Accessed 28 Aug 2020

Perlea P, Nistor C, Suciu I (2016) Post-treatment periapical periodontitis X-ray versus CBCT - a case report. J Med Life 9(1):84-87

Pjetursson BE, Thoma D, Jung R, Zwahlen M, Zembic A (2012) A systematic review of the survival and complication rates of implant-supported fixed dental prostheses (FDPs) after a mean observation period of at least 5 years. Clin Oral Implants Res 23(Suppl 6):22-38

Premium Market Insights, Reports MDI. Dental Implants Market to 2027 Global Analysis and Forecasts by Product (Dental Bridges, Dental Crowns, Dentures, Abutments, and Others); Material (Titanium Implants \& Zirconium Implants); End User (Hospitals \& Clinics, Dental Laboratories, and 
Others) and Geography Mar-2019. https://www.premiummarketinsight s.com/reports-tip/dental-implants-market: Accessed 28 Aug 2020

Sadid-Zadeh R, Kutkut A, Kim H (2015) Prosthetic failure in implant dentistry. Dent Clin North Am 59(1):195-214

Saghiri MA, Saghiri AM (2017) In memoriam: Dr. Hajar Afsar Lajevardi MD, MSC, MS (1955-2015), Iran. J Pediatr 27:e8093. https://doi.org/10.5812/ijp.8093

Sahiwal IG, Woody RD, Benson BW, Guillen GE (2002a) Radiographic identification of threaded endosseous dental implants. J Prosthet Dent 87(5):563-577

Sahiwal IG, Woody RD, Benson BW, Guillen GE (2002b) Radiographic identification of nonthreaded endosseous dental implants. J Prosthet Dent 87(5):552-562

Sahiwal IG, Woody RD, Benson BW, Guillen GE (2002c) Macro design morphology of endosseous dental implants. J Prosthet Dent 87(5):543-551

Sailer I, Makarov NA, Thoma DS, Zwahlen M, Pjetursson BE (2015) All-ceramic or metal-ceramic tooth-supported fixed dental prostheses (FDPs)? A systematic review of the survival and complication rates. Part l: Single crowns (SCs). Dent Mater. 31(6):603-23

Shah N, Bansal N, Logani A (2014) Recent advances in imaging technologies in dentistry. World J Radiol 6(10):794-807 site AAID. American Acadamy of Implant Industry. Available from: https:// www.aaid-implant.org/faq/\#267 Accessed 28 Aug 2020

Takeuchi Y, Koizumi H, Furuchi M, Sato Y, Ohkubo C, Matsumura H (2018) Use of digital impression systems with intraoral scanners for fabricating restorations and fixed dental prostheses. J Oral Sci 60:1-7

Tuzoff D. Denti.Al 2017. https://www.denti.ai/: Accessed 28 Aug 2020

Vahidi F, Pinto-Sinai G (2015) Complications associated with implant-retained removable prostheses. Dent Clin North Am 59(1):215-226

Vidor MM, Liedke GS, Vizzotto MB, da Silveira HLD, da Silveira PF, Araujo CW et al (2017) Imaging evaluating of the implant/bone interface-an in vitro radiographic study. Dentomaxillofac Radiol 46(5):20160296

whatimplantisthat. https://www.whatimplantisthat.com/\#. Accessed 28 Aug 2020

\section{Publisher's Note}

Springer Nature remains neutral with regard to jurisdictional claims in published maps and institutional affiliations.

\section{Submit your manuscript to a SpringerOpen ${ }^{\circ}$ journal and benefit from:}

- Convenient online submission

- Rigorous peer review

- Open access: articles freely available online

- High visibility within the field

- Retaining the copyright to your article

Submit your next manuscript at $\gg$ springeropen.com 